See discussions, stats, and author profiles for this publication at: https://www.researchgate.net/publication/269155129

\title{
Effect of Cooling on the Behaviour of a Steel Beam under Fire Loading including the End Joint Response
}

Conference Paper · September 2003

DOI: $10.4203 /$ ccp. 77.65

\section{CITATIONS}

11

4 authors:

6

Aldina Santiago

University of Coimbra

118 PUBLICATIONS 1,145 CITATIONS

SEE PROFILE

Paulo Vila Rea

University of Aveiro

212 PUBLICATIONS 1,552 CITATIONS

SEE PROFILE

\section{READS}

371

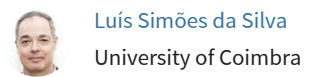

589 PUBLICATIONS 5,603 CITATIONS

SEE PROFILE

Jean-Marc Franssen

University of Liège

205 PUBLICATIONS 3,183 CITATIONS

SEE PROFILE

Some of the authors of this publication are also working on these related projects:

EQUALJOINTS (2013-2016): European pre-qualified steel joints. Fund for Coal and Steel Grant Agreement No. RFSR-CT-2013-00021 View project

EQUALJOINTS-PLUS (2017-2019): Valorisation of knowledge for European pre-qualified steel joints. Fund for Coal and Steel Grant Agreement No. 754048 (2017) View project 


\title{
Effect of cooling on the behaviour of a steel beam under fire loading including the end joint response
}

\author{
A. Santiago ${ }^{*}$, L. Simões da Silva ${ }^{*}$, P. Vila Real ${ }^{+}$and J.M. Franssen ${ }^{\#}$ \\ "Department of Civil Engineering, \\ University of Coimbra, Portugal \\ ${ }^{+}$Civil Engineering Department, \\ University of Aveiro, Portugal \\ ${ }^{\#}$ Department M\&S, \\ University of Liege, Belgium
}

\begin{abstract}
This paper investigates the influence of axial and rotational restraint on the response of a steel beam subjected to fire loading. Additionally, it is the objective of the present paper to compare the behaviour of a beam subjected to the ISO 834 fire and a real fire (including the heating and cooling phases). To this purpose, an IPE 200 cross section beam with span $5 \mathrm{~m}$ and steel class S275 was chosen and analysed under a representative uniformly distributed load of $14 \mathrm{kN} / \mathrm{m}$ and two alternative thermal loads as described above. The program SAFIR was chosen to carry out the numerical simulations, which allows for large displacements and the use of nonlinear temperature dependent material properties. The parametric study considered variations in the boundary conditions at the left support of the beam, from simplysupported to fixed, with various levels of axial and rotational restraint. The results highlight distinct behaviour between the ISO fire curve and the real fire and indicate that strain reversal plays an important role in the behaviour of real structures.
\end{abstract}

Keywords: Structural Engineering, Semi-Rigid Behaviour, Steel Structures, Component Method, Temperature, Fire Resistance.

\section{Introduction}

Observation of steel structures that suffered fire events has shown that many collapses take place after the fire is extinguished and the steel structural elements start to cool down. On several occasions, the steel joints fail from their tensile components (such as bolts or end-plate), because of high strains induced by the thermal shortening that occurs during cooling.

Most current design codes for the fire resistance of a steel beam are based on tests performed on simply supported beams subjected to the ISO 834 fire curve [1]. However these 'standard' fire experiments do not represent a real fire. The temperature history during a real fire can be described by three main stages: growth, 
full development and decay. The high temperatures in the second phase represent the greatest challenge to structural stability, possibly leading to structure collapse. In cases where damage caused is clearly limited, remedial action is necessary in the members that suffered irreversible damage. The assessment of the damage can be done by the evaluation of residual deformations and the development of stresses during the whole period of fire exposure.

The residual effects in members around the fire zone of a frame after cooling has taken place result from interaction between the thermal effects on these members and restraints from the adjacent structure. During the heating phase, a beam tends to expand due to the thermal expansion and to bend due to the loads applied on a softening material, these actions being partially resisted by the adjacent cooler structure. Additionally, extensive yielding of the beam is usually observed because of the reduction of the yield stress with increasing temperature. If failure does not occur during the heating phase, subsequent cooling causes the beam to re-stiffen and contract. Previous development of yield strains means that elastic unloading leads to residual deformations and a redistribution of internal forces that may induce tensile forces at the supports (joints). These tensile forces may finally lead to failure of the joints from their tensile components (such as bolts or end-plate) and consequently to the failure in the structure (Figure 1).

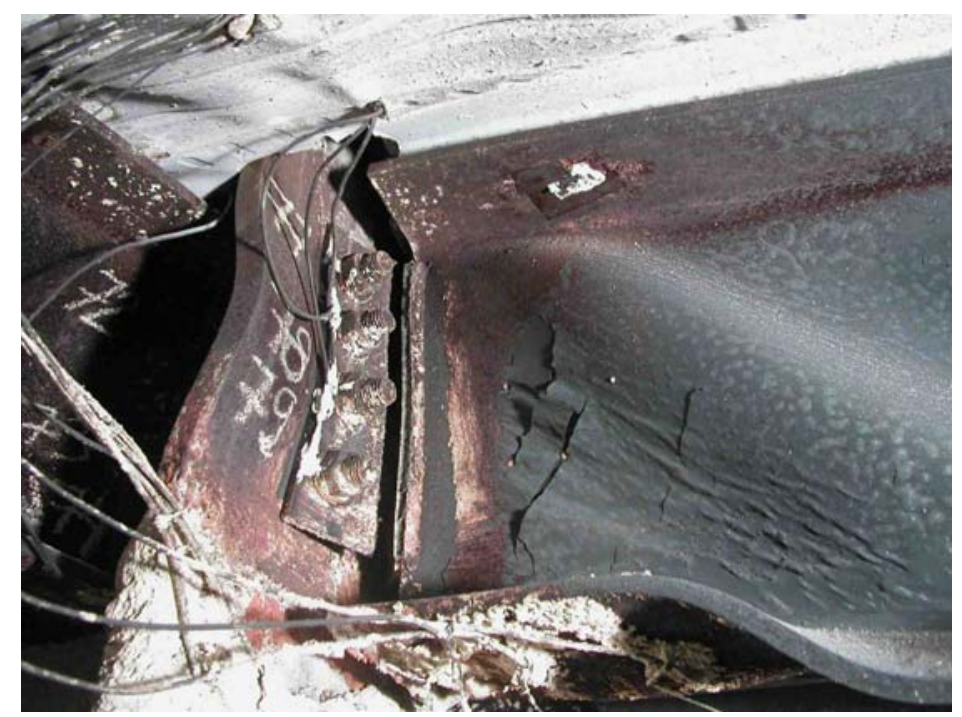

Figure 1: Fracture of the end-plate

A methodology for the analysis of steel joints at high temperatures has recently been proposed by some of the authors [2], that enables the evaluation of the moment rotation response under fire loading. In particular, it highlighted the relevance of the combined levels of bending moment and axial force on the failure of the joint. Given the coupled nature of the development of stresses and deformations in a beam-joint substructure, it is the objective of the present paper to analyse the behaviour of that system when subjected to a real fire, including the cooling phase, and to assess the influence of the joint bending and axial flexibility on the overall response of the system. 


\section{Thermal-Mechanical Properties of Steel and Steel Connectors at High Temperature}

The major influence of temperature on the mechanical properties of steel is a reduction of yield stress, ultimate stress and Young's modulus with increasing temperature. Table 1 reproduces the reduction factors for stiffness and strength of steel used in beam and connections with increasing temperature as recommended in Eurocode 3 [3]: a reduction of stiffness starting at a temperature of around $100^{\circ} \mathrm{C}$, while strength (yield stress) starts to reduce at about $400^{\circ} \mathrm{C}$. Similarly, Table 1 illustrates the corresponding strength reduction factors for bolts and welds.

Table 1: Reduction factors for yield stress, $f_{y}$, and Young's modulus, $E_{a}$, at temperature $\theta_{a}$,

\begin{tabular}{|c|c|c|c|c|}
\hline \multirow{3}{*}{$\begin{array}{c}\text { Temperature } \\
\theta_{a}\end{array}$} & \multicolumn{4}{|c|}{ Reduction factors } \\
\hline & \multicolumn{2}{|c|}{$\begin{array}{l}\text { for yield stress, } f_{y} \text {, and Young's } \\
\text { modulus, } E_{a}, \text { for steel }\end{array}$} & \multirow{2}{*}{$\begin{array}{c}\text { for bolts } \\
\text { (tension and shear) } \\
k_{b, 2} \\
\end{array}$} & \multirow{2}{*}{$\begin{array}{c}\text { for welds } \\
k_{w, 2}\end{array}$} \\
\hline & $k_{y, \theta}=f_{y, \theta} / f_{y}$ & $k_{E, \theta}=E_{a, \theta} / E_{a}$ & & \\
\hline $20^{\circ} \mathrm{C}$ & 1.000 & 1.000 & 1.000 & 1.000 \\
\hline $100^{\circ} \mathrm{C}$ & 1.000 & 1.000 & 0.968 & 1.000 \\
\hline $150^{\circ} \mathrm{C}$ & 1.000 & 0.950 & 0.952 & 1.000 \\
\hline $200^{\circ} \mathrm{C}$ & 1.000 & 0.900 & 0.935 & 1.000 \\
\hline $300^{\circ} \mathrm{C}$ & 1.000 & 0.800 & 0.903 & 1.000 \\
\hline $400^{\circ} \mathrm{C}$ & 1.000 & 0.700 & 0.775 & 0.876 \\
\hline $500^{\circ} \mathrm{C}$ & 0.780 & 0.600 & 0.550 & 0.627 \\
\hline $600^{\circ} \mathrm{C}$ & 0.470 & 0.310 & 0.220 & 0.378 \\
\hline $700^{\circ} \mathrm{C}$ & 0.230 & 0.130 & 0.100 & 0.130 \\
\hline $800^{\circ} \mathrm{C}$ & 0.110 & 0.090 & 0.067 & 0.074 \\
\hline $900^{\circ} \mathrm{C}$ & 0.060 & 0.0675 & 0.033 & 0.018 \\
\hline $1000^{\circ} \mathrm{C}$ & 0.040 & 0.0450 & 0.000 & 0.000 \\
\hline $1100^{\circ} \mathrm{C}$ & 0.020 & 0.0225 & 0.000 & 0.000 \\
\hline $1200^{\circ} \mathrm{C}$ & 0.000 & 0.000 & 0.000 & 0.000 \\
\hline
\end{tabular}

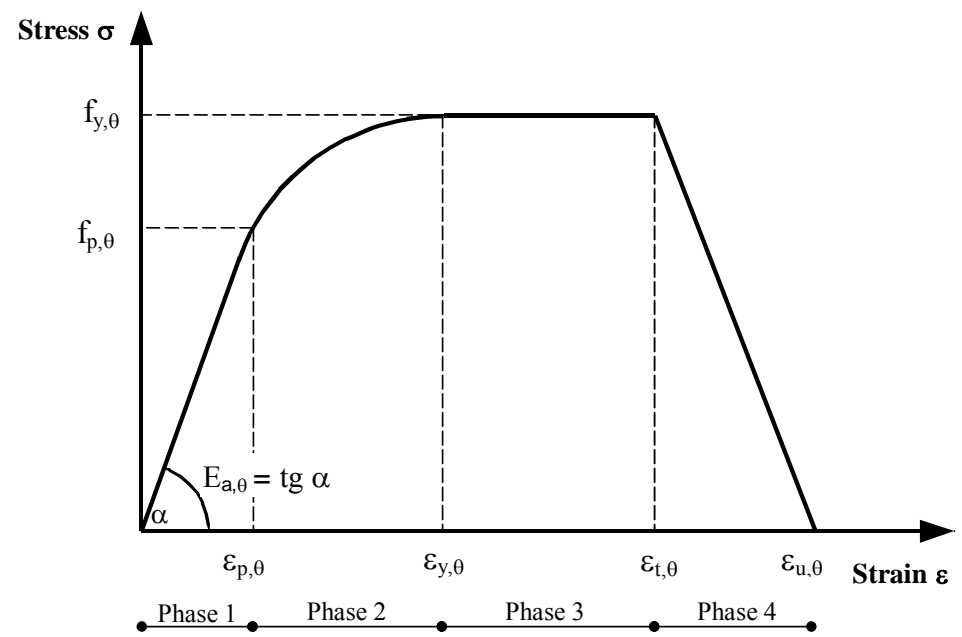

Figure 2: Stress-strain relationships for steel at high temperature 
The corresponding stress-strain diagram for steel at elevated temperatures, shown in Figure 2, exhibits four distinct zones, namely: phase 1 - a linear zone, phase 2 - an elliptic transition curve, phase 3 - a constant stress zone, and phase 4 - a linear softening branch.

\section{Numerical Analysis of Beam-Joint System}

\subsection{Generalities}

In order to explore the behaviour of a beam-joint system under fire loading, the beam model of Figure 3 was adopted. It consists of an IPE 200 cross-section beam with a span of $5 \mathrm{~m}$ and steel S275, with an unfactored plastic moment resistance at room temperature of $60.67 \mathrm{kNm}$.

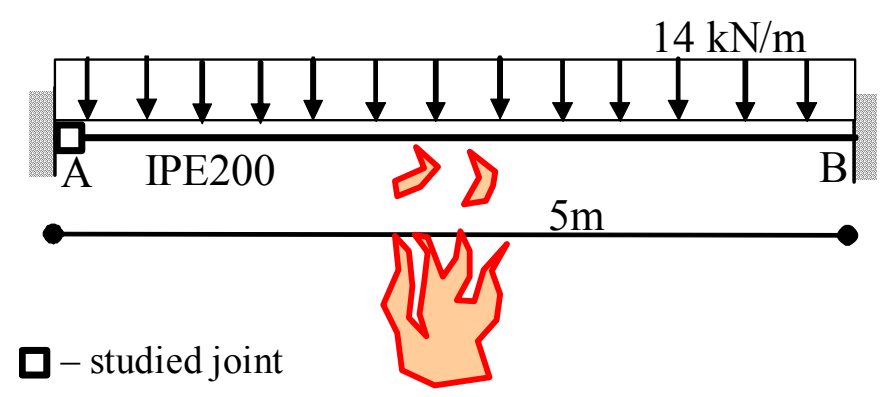

Figure 3: Beam model.

Mechanical and thermal properties for steel at ambient temperature were taken from part 1.2 of EC1 [1] and part 1.2 of EC3 [3] and are summarized in Table 2:

Table 2: Mechanical and thermal properties of steel.

\begin{tabular}{cc}
\hline Yield stress & $\mathrm{f}_{\mathrm{y}}=275 \mathrm{MPa}$ \\
\hline Young modulus & $\mathrm{E}=210 \mathrm{GPa}$ \\
\hline Density & $7850 \mathrm{~kg} / \mathrm{m}^{3}$ \\
\hline Poisson's ratio & 0.3 \\
\hline Convection coefficient of hot surface & 25 \\
\hline Convection coefficient of cold surface & 9 \\
\hline Relative emissivity & 0.5 \\
\hline
\end{tabular}

Additionally, the temperature dependent functions recommended by EC3 were adopted in the analysis.

To simplify the analysis of the coupling between beam and joint, the beam end B was assumed built-in in all simulations, while several possibilities were tested for beam end A. The applied mechanical loading, assumed to represent a typical serviceability condition of an office building, was a constant uniformly distributed load of $14 \mathrm{kN} / \mathrm{m}$. Two alternative thermal loadings were assumed: a) standard temperature-time exposure, curve ISO834; and b) heating and cooling curve, both 
illustrated in Figure 4. Finally, the beam faces and joint were assumed unprotected and all beam faces and joint were exposed to the fire load.

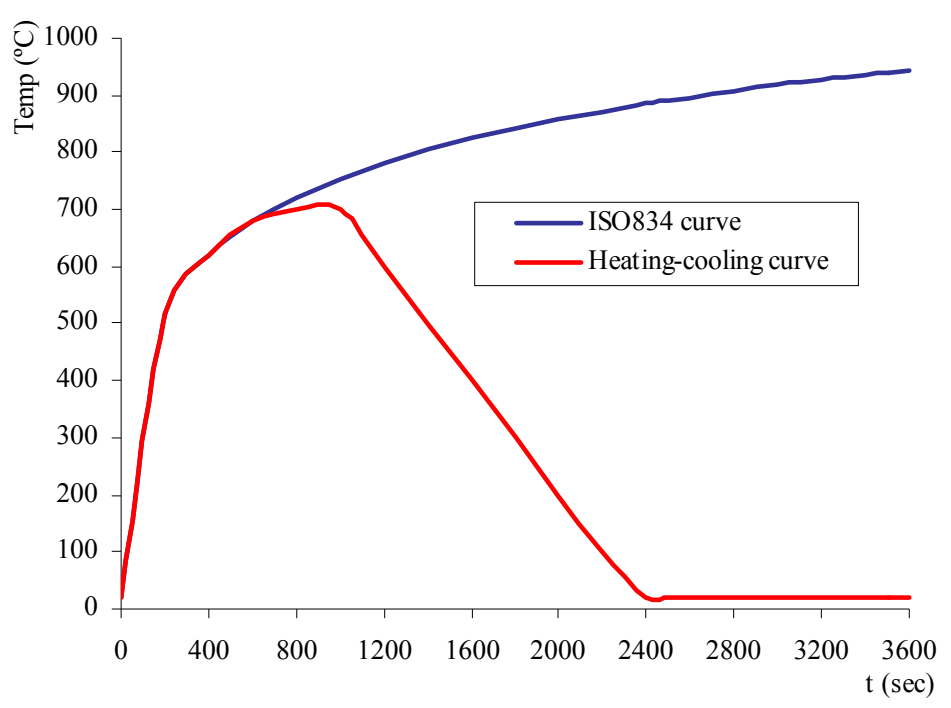

Figure 4: Temperature-time curves.

\subsection{The SAFIR Program}

\subsubsection{Introduction}

The program SAFIR [4] was chosen to carry out the numerical simulations, which is a finite element code for geometrical and material non-linear analysis, specially developed at the University of Liege for studying structures subjected to fire. According to this program, the analysis of a structure exposed to fire conditions involves two independent and successive steps:

1) the first step involves the prediction of the temperature distribution within the structural member (thermal analysis) and,

2) the second step is carried out to determine the structure response due to the mechanical and thermal load (mechanical analysis) in a transient regime.

\subsubsection{Thermal analysis}

The thermal analysis follows the temperature-time curves input by the user as boundary conditions to the various element faces. 3-D solid elements or 2-D plane elements are available and it is possible to select different materials in order to consider protection materials. From this analysis, the temperatures across the crosssection are obtained and are stored for subsequent structural analyses.

\subsubsection{Mechanical analysis}

The transient analysis of the mechanical behaviour of the structure uses the results from the previous analysis. Bar, beam, shell and solid elements are available. As the 
computation strategy is based on an incremental procedure, the following information is provided by the software at each time-step:

- Displacements at each node of the structure;

- Axial and bending moments at integration points in each elements;

- Strains, stresses and tangent modulus in each fibre of each element.

In SAFIR, large displacements as well the effect of thermal strains are considered. The material properties are non-linearly temperature dependent (according, for steel, to Figure 2 and to the reduction factors of Table 1) and material unloading is parallel to the elastic loading branch. The structural collapse is defined by a negative stiffness matrix. Local failure of a structural member that does not induce collapse of the structure can be handled by means of the arc-length technique.

In the following, 2D beam elements were used throughout the numerical study. The beam element is straight in its un-deformed geometry. Lateral-torsional buckling is not allowed (2D element).

\subsection{Numerical results}

\subsubsection{Thermal analysis}

Using the thermal tool of SAFIR and the temperature-time curves of Figure 4, the temperature contour plots of Figure 5 are obtained. It can be observed that the web

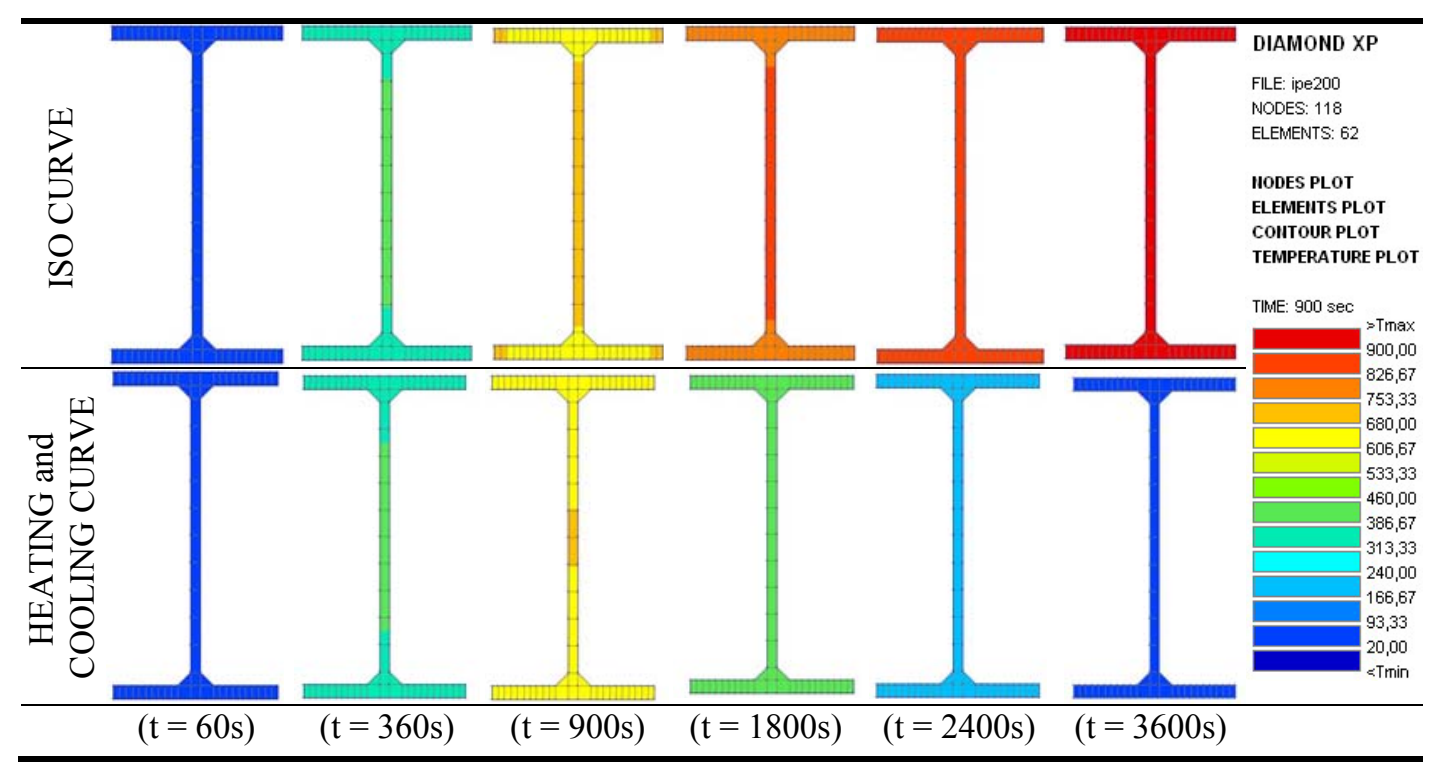

Figure 5: Temperature distribution within the cross-section of the beam

and the tips of the flanges yield the highest temperatures. The variation of the midweb temperature with time is shown in Figure 6. The maximum temperature was reached at time $\mathrm{t}=1040$ s for the real fire curve while it continuously increases with the ISO curve. When the temperature starts to rise, the beam stays cooler than the 
compartment; however this difference decreases at high temperature. If is applied a natural fire, it is observed that during the cooling phase the compartment temperature decreases faster than the beam temperature.

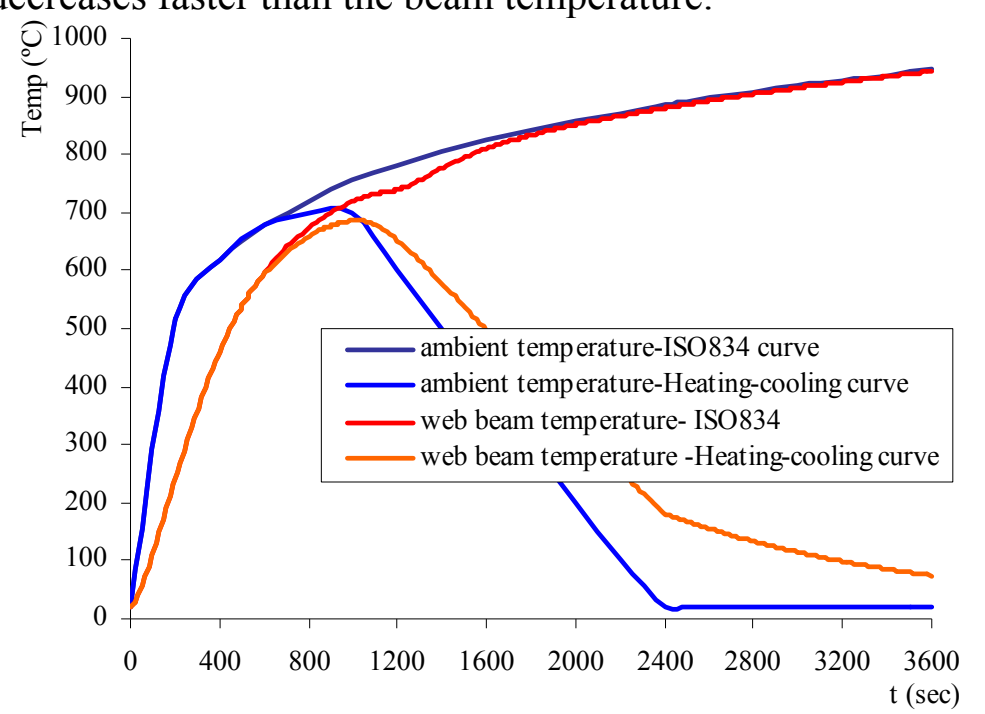

Figure 6: Variation of the mid-web temperature using both heating strategies

\subsubsection{The reference case: comparative behaviour under ISO fire and real fire of an axially restrained pinned-fixed beam}

In order to provide a basis for subsequent comparisons, the reference case was chosen to have free rotation and fixed translations at beam end A. Figure 7 shows the development of axial force in the beam with increasing time (Figure 7a) or with increasing temperature (Figure 7b). Four distinct stages can be identified: (i) Stage I - increase of axial force with temperature as beam expands, its thermal expansion being converted into thermal stresses which increase the overall stress level in the beam without significant bending deformations; (ii) Stage II - decrease of axial force probably induced by the bending deformation of the beam induced by the axial restraint and the initial deformation due to the applied mechanical loading and the change of E-modulus with temperature; (iii) Stage III - characterized by complete

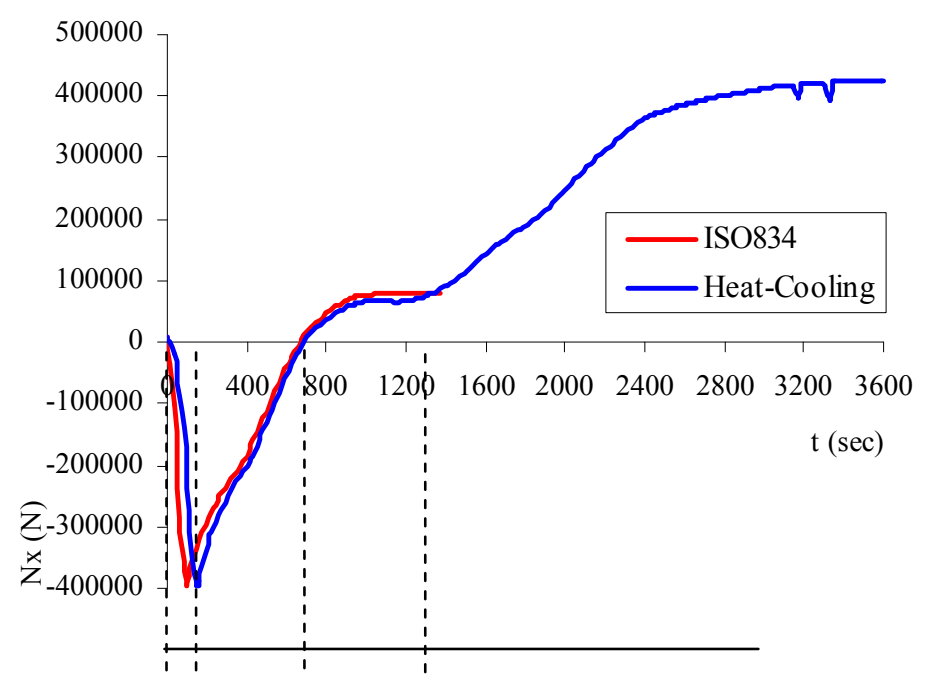




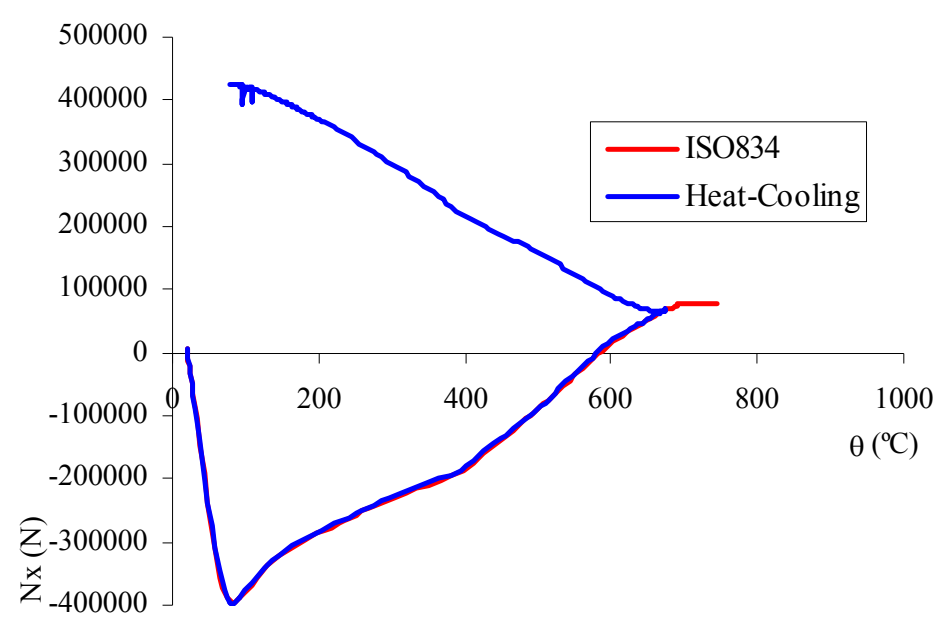

Figure 7: Axial force in the beam.

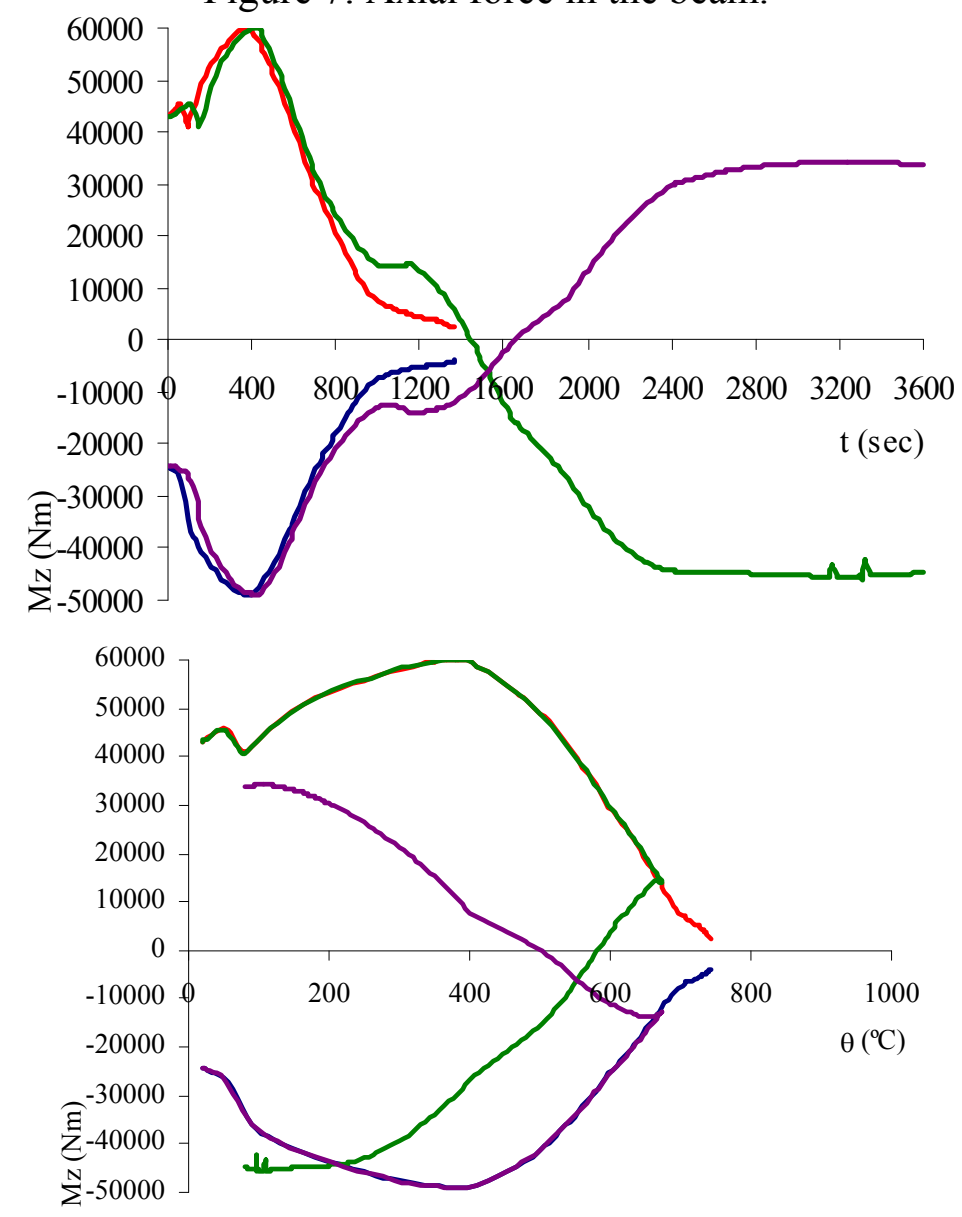

$$
\begin{aligned}
& - \text { fixed joint B (ISO834) } \\
& \text { mid-span beam (ISO834) } \\
& \text { fixed joint B (Heat-Cooling) } \\
& \text { mid-span beam (Heat-Cooling) }
\end{aligned}
$$

Figure 8: Bending moment in the beam. 


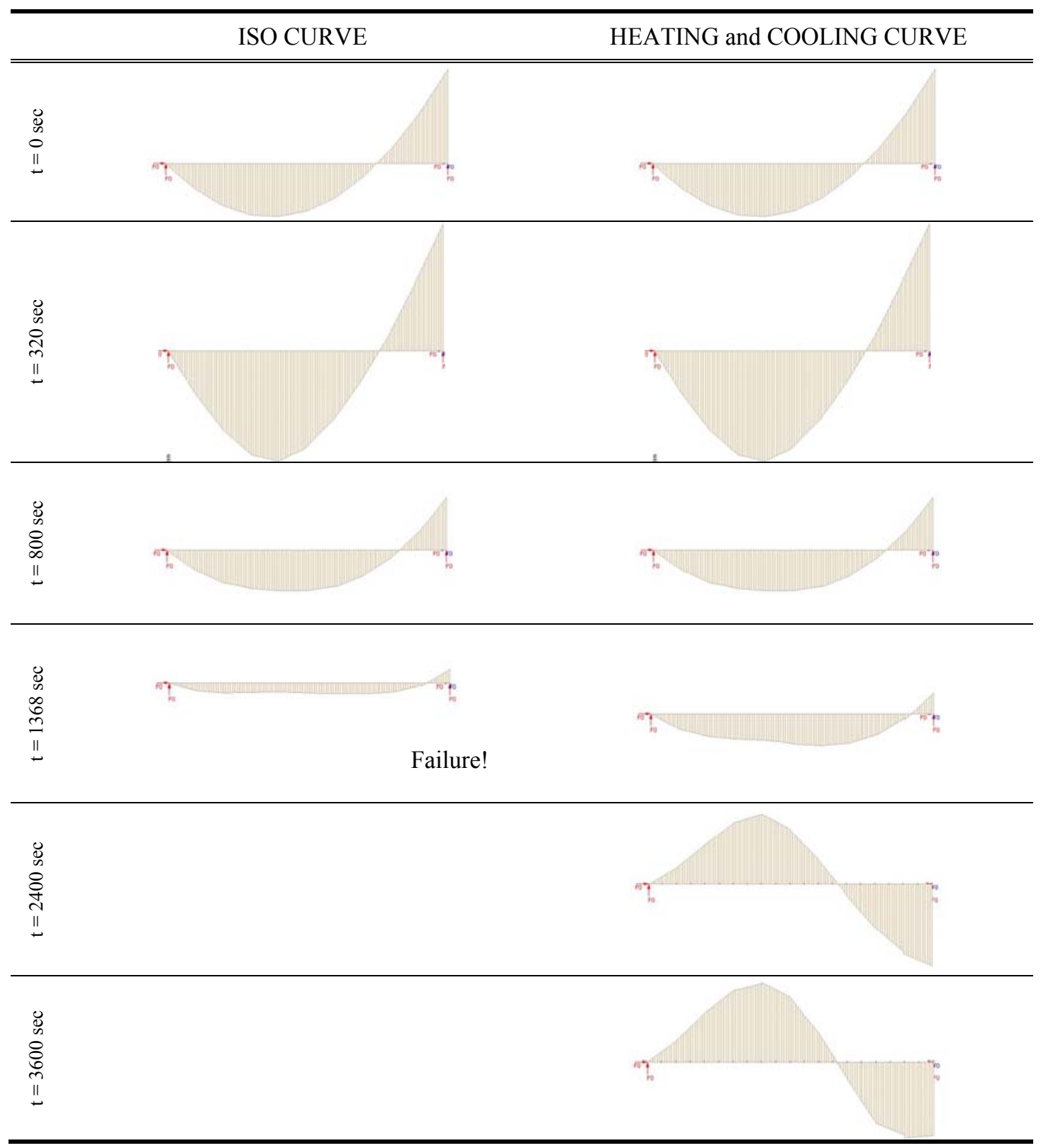

Figure 9: Bending moment diagrams.

inversion of the level of axial force $\left(\mathrm{N}<\mathrm{N}_{20^{\circ} \mathrm{C}}\right.$, where $\mathrm{N}_{20^{\circ} \mathrm{C}}$ denotes the service load at the beginning of heating) and increased vertical deflection of the beam because of material strength degradation; (iv) Stage IV - development of catenary action, with increased tensile axial force.

Figure 8 shows the variation of bending moment with time or temperature at midspan and at the fixed end. Initially, both the mid-span and end-moments increase from initial values of $24.65 \mathrm{kNm}$ and $43.75 \mathrm{kNm}$, respectively. This is followed by a reduction at about $400{ }^{\circ} \mathrm{C}$. For the ISO curve, the beam eventually fails at a temperature of $750^{\circ} \mathrm{C}$. For the real fire curve, where cooling starts before failure of the beam, there is a general increase in sagging and below about $550^{\circ} \mathrm{C}$ the bending 


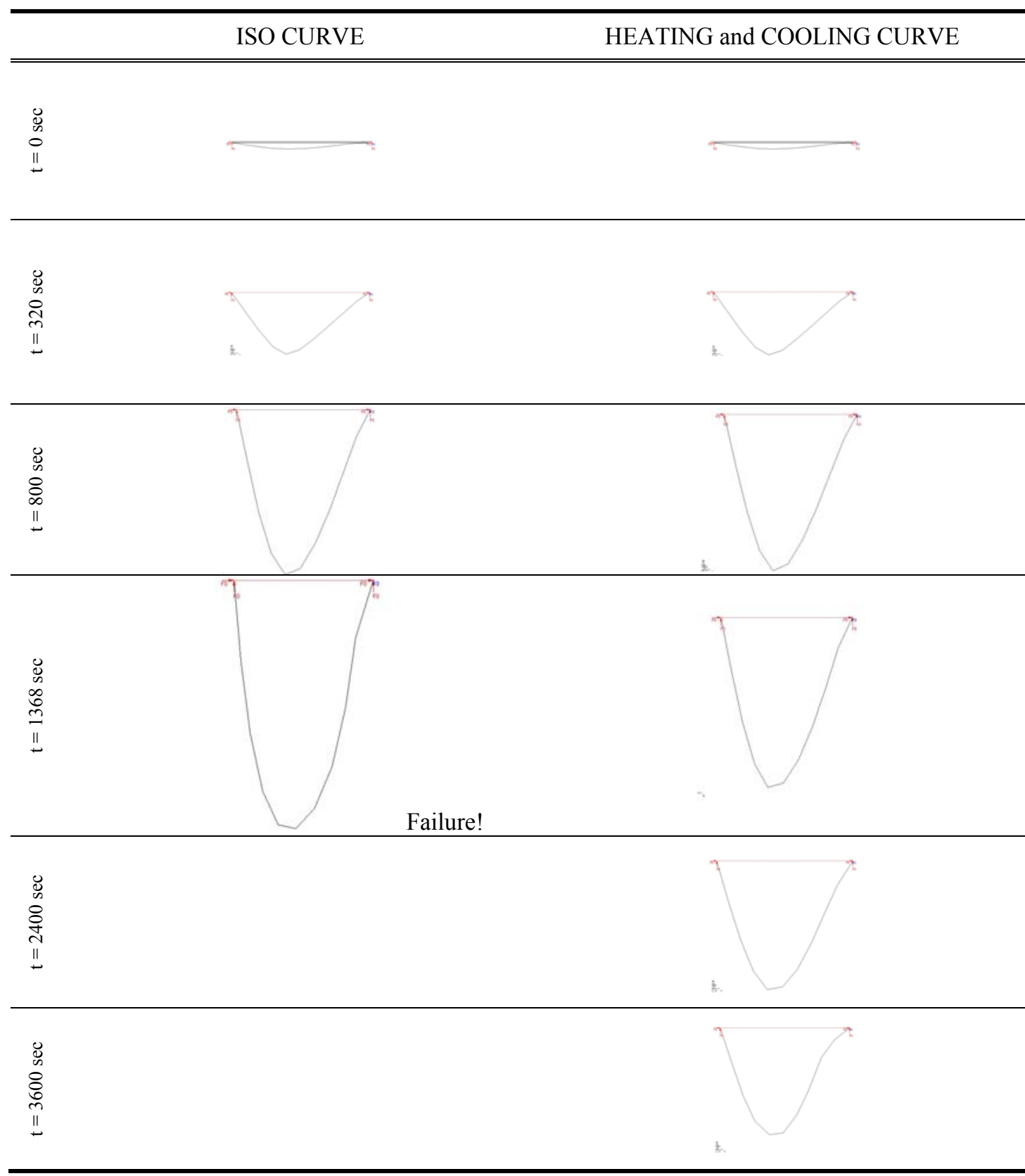

Figure 10: Deformed meshes.

moments change sign, the residual moments for the cooled beam being roughly similar to the original values but with reversed sign. Figures 9 and 10 illustrate the bending moment diagrams and the vertical deflection of the beam for chosen times.

As can be seen from Figure 11, the variation of mid-span deflection is markedly different at each stage. At Stage I and II the rate of deformation is quite gradual, as the temperature rises above $550^{\circ} \mathrm{C}$ (Stage III) the rate of deformation increases significantly and the failure occurs around $750^{\circ} \mathrm{C}$. If it is allowed to cool before failure, the deflection reverses. However, since the material has been stressed 

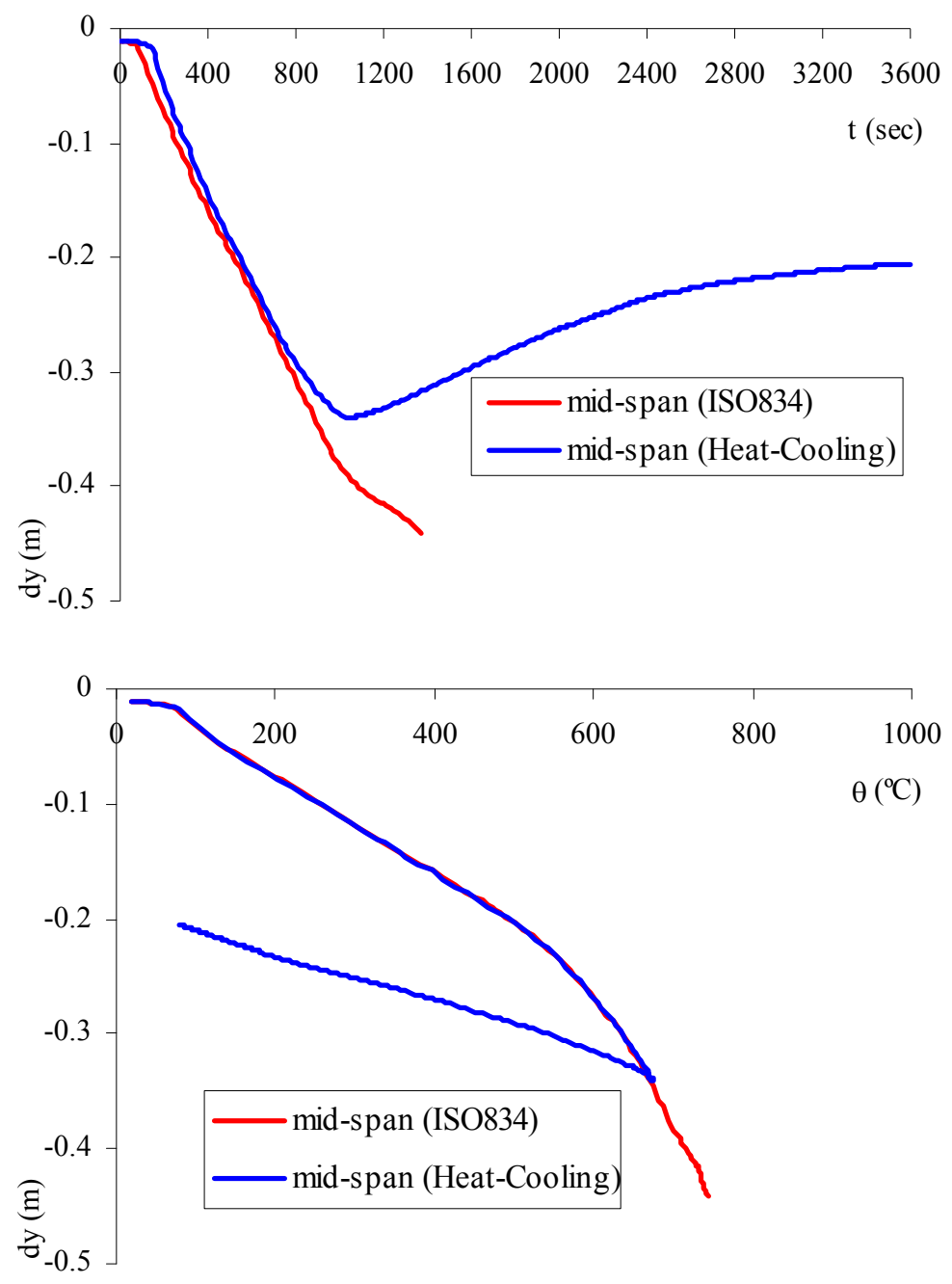

Figure 11: Vertical displacement of the mid-span beam.

beyond the elastic limit, the corresponding strain does not follow the same stressstrain path as during the heating phase and a residual deflection is created.

\subsubsection{Influence of axial restraint}

In order to assess the influence of the axial restraint on the response of the beam, the previous results are compared with a simply-supported-fixed beam (SS-F), with free longitudinal displacement at beam end A. Figure 12 depicts the comparative results of both cases. Examination of this Figure shows that the SS-F beam fails during the heating phase, no difference being thus observed between the ISO and the real fire curves. The fact that a beam with axial restraint can withstand much higher temperatures is consistent with what has been observed in the Cardington fire tests [7]. 


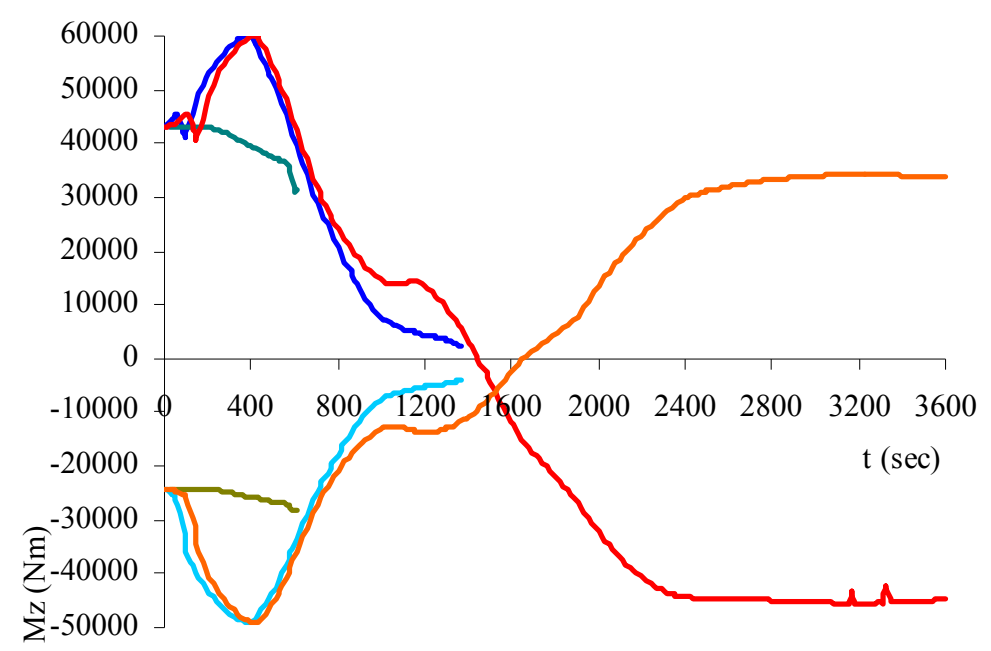

\begin{tabular}{|l|l|}
\hline & Fixed joint B (case P-F) H-Cooling \\
\hline & Mid-span (case P-F) H-Cooling \\
\hline & Fixed joint B (case SS-F) ISO834 \\
\hline & Mid-span (case SS-F) ISO834 \\
\hline & Fixed joint B (case P-F) ISO834 \\
\hline & Mid-span (case P-F) ISO834 \\
\hline
\end{tabular}

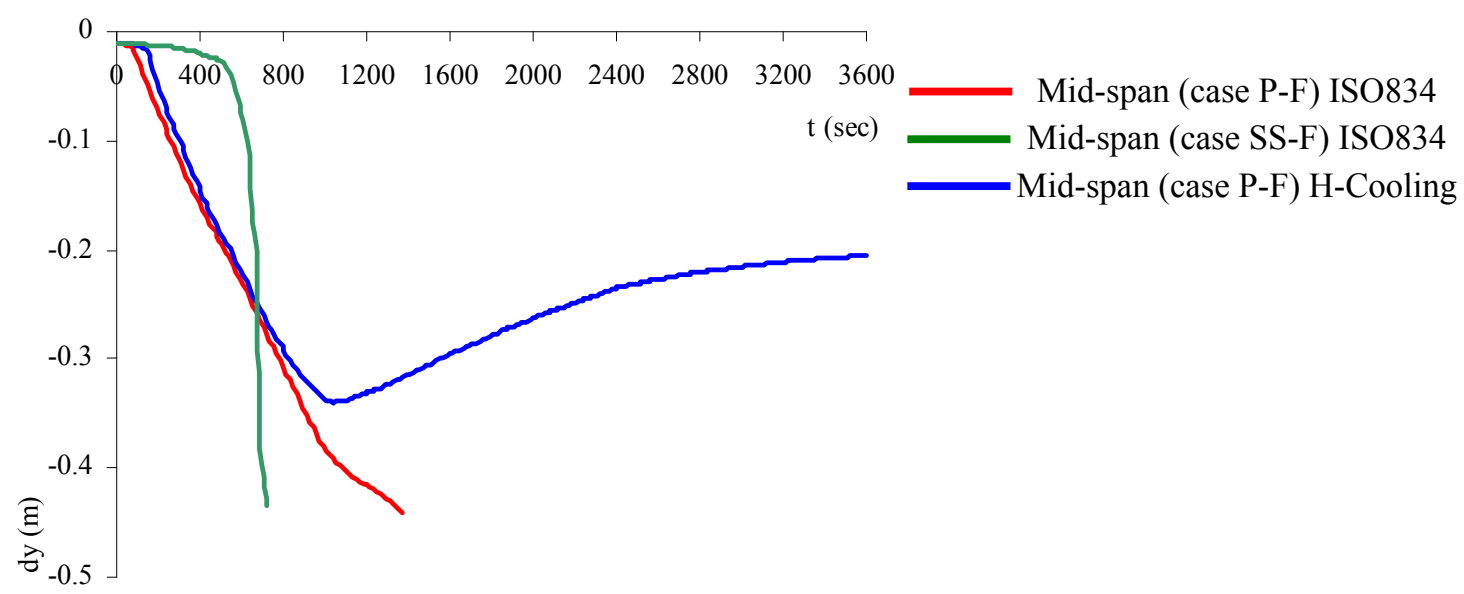

Figure 12: Bending moments and vertical displacement.

\subsubsection{Coupled behaviour including end-joint response}

To evaluate the influence of the joint stiffness on the behaviour of the beam, several combinations of axial and bending stiffness at the left support were tested. As a nondimensional measure of the relative stiffness of beam and joint, the axial restraint ratio $\beta_{\mathrm{L}}$ and the rotational restraint ratio $\beta_{\mathrm{R}}$ are used, defined by the following expressions:

$\beta_{\mathrm{L}}=K_{L} /\left(\mathrm{E}_{20^{\circ} \mathrm{C}} \mathrm{A}_{\mathrm{b}} / \mathrm{l}_{\mathrm{b}}\right)$

$\beta_{\mathrm{R}}=K_{R} /\left(4 \mathrm{E}_{20{ }^{\circ} \mathrm{C}} \mathrm{I}_{\mathrm{b}} / \mathrm{l}_{\mathrm{b}}\right)$ 
$K_{L}$ and $K_{R}$ denote the axial stiffness and the rotational stiffness of the joint, at $20^{\circ} \mathrm{C}$, $\mathrm{A}_{\mathrm{b}}$ denotes the beam cross-section area, and $\mathrm{E}_{20^{\circ} \mathrm{C}} \mathrm{A}_{\mathrm{b}} / \mathrm{l}_{\mathrm{b}}$ and $4 \mathrm{E}_{20^{\circ} \mathrm{C}} \mathrm{I}_{\mathrm{b}} / \mathrm{l}_{\mathrm{b}}$ are the elastic axial stiffness and flexural stiffness of the beam at ambient temperature, respectively.

The selected cases are summarized in Table 3, representing practical extremely weak to extremely strong axial and rotational restraint:

Table 3: Selected combinations of axial and rotational joint restraint

\begin{tabular}{cccc}
\hline & $\beta_{\mathrm{L}}$ & $\beta_{\mathrm{R}}$ & Comments \\
\hline \hline Case 1a & 0.0003 & 0 & weak axial restraint \\
\hline Case 1b & 0.146 & 0 & medium axial restraint \\
\hline Case 1c & 2.780 & 0 & weak rotational restraint \\
\hline Case 2a & 2.780 & 0.0003 & medium rotational restraint \\
\hline Case 2b & 2.780 & 2.73 & very strong rotational restraint \\
\hline Case 2c & 2.780 & $\infty$ &
\end{tabular}

Case 1 examines the influence of axial flexibility at the beam-end A. Case 1a, with negligible axial stiffness, behaves similarly to the simply supported - fixed case, the beam failing during the heating phase. Conversely, Case 1c, with high axial stiffness, reproduces the reference case of pinned-fixed support conditions and Case $1 \mathrm{~b}$ represents an intermediate situation. Figures 13 to 14 compare the three situations both for the ISO and the real fire curves.

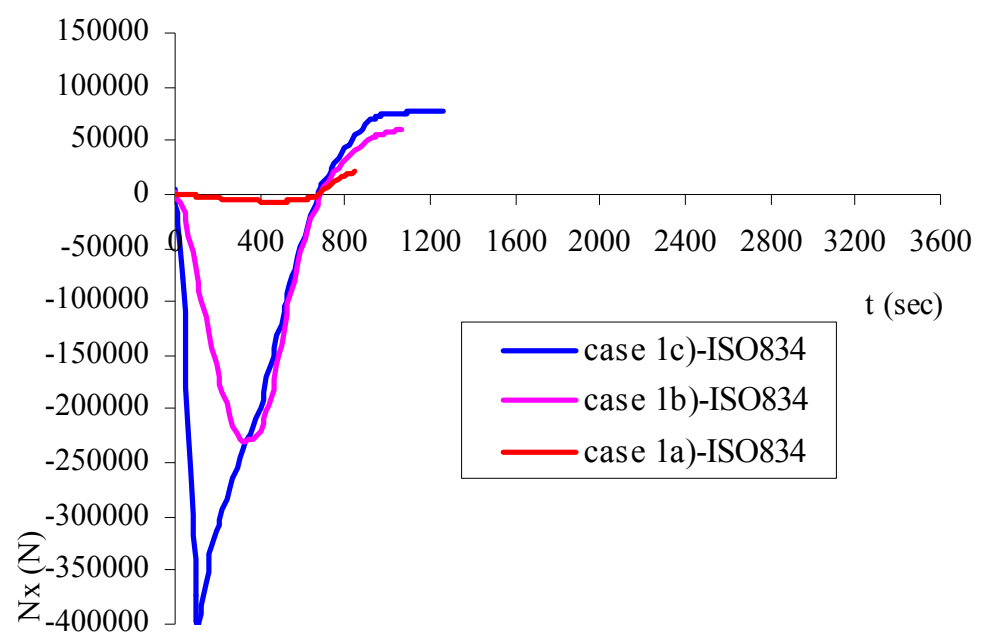




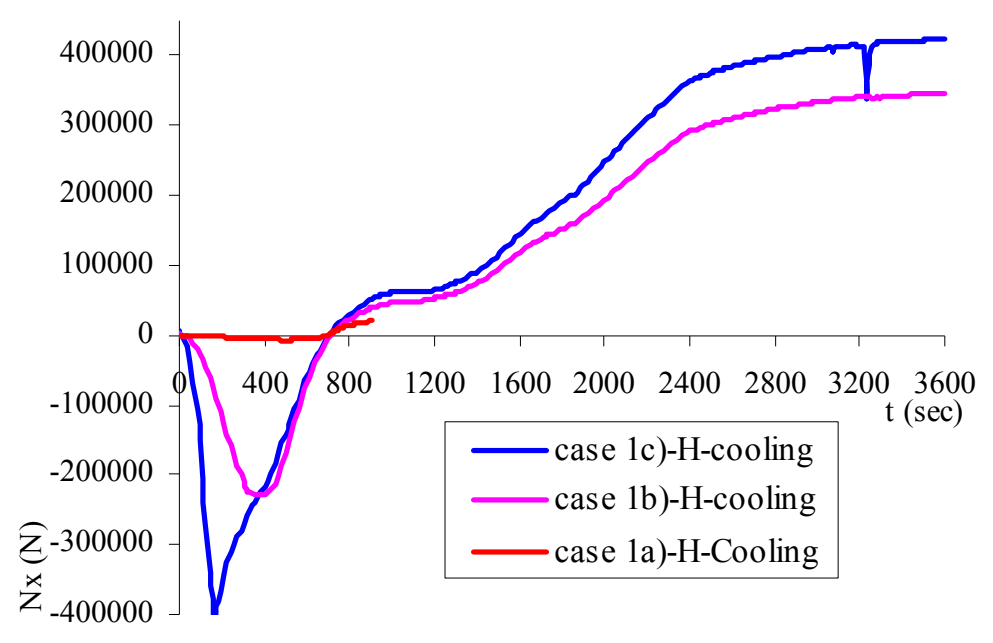

Fig. 13 Development of beam axial force.
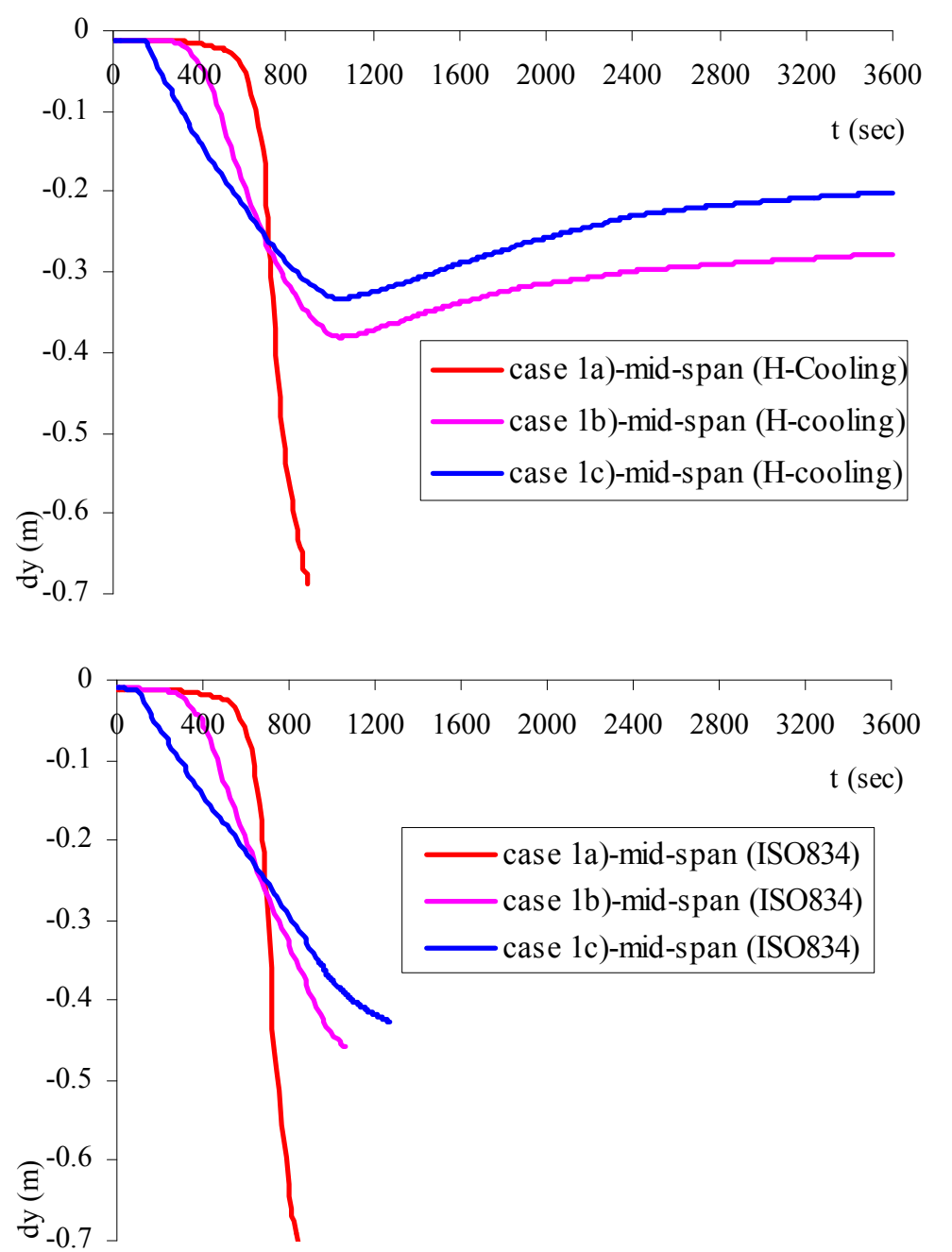

Fig. 14 Development of beam mid-span deflection. 

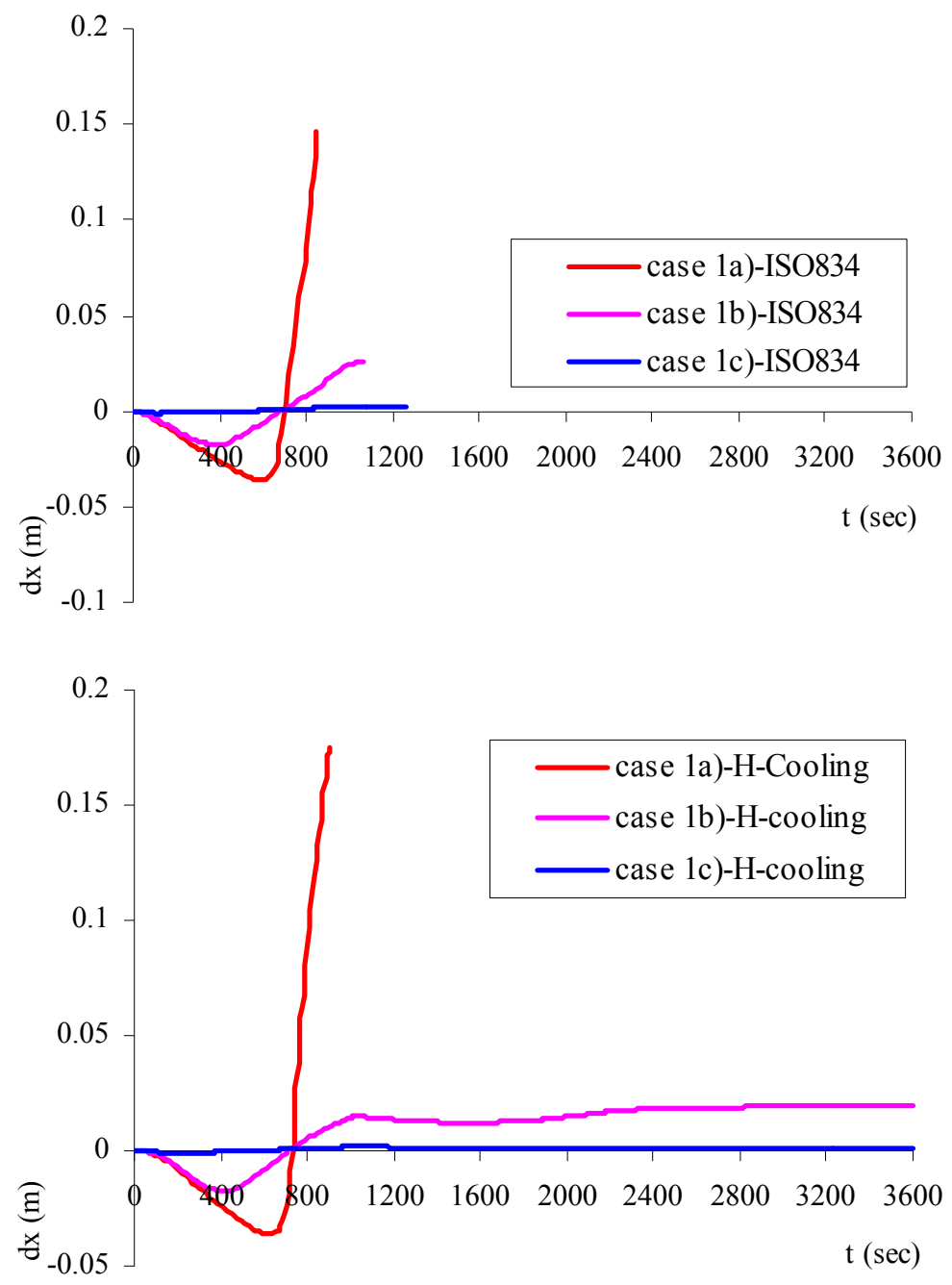

Fig. 15 Development of horizontal displacement.

Examination of Figure 14, that illustrates the variation of mid-span deflection, shows that at the third stage, mid-span deflection for case 1b) does not develop at an accelerating rate, which implies that the response of the beam is largely influenced by the axial restraint. This conclusion contradicts the traditional assumption that states that, as the material continues to deteriorate, deflection rate increases until collapse. This statement is only correct for simple determinate structures, such as usually tested under standard fire tests, or redundant structures once all load carrying paths have been exhausted (case 1a).

Finally, comparing Figures 14 and 15, it is observed that because of no axial displacement in case c), the vertical displacement of the beam starts very early but the maximum displacement at the failure is lower than for the others cases. It indicates that, while the axial restraint may not significantly modify the load capacity, the deflection is substantially reduced. If the beam is allowed to cool before failure, the deflection reverses and the residual deformations of case $1 \mathrm{~b}$ ) at the end is lower than case 1a). 
Case 2 studies the influence of rotational stiffness for a fixed value of axial restraint, for the two fire strategies described above. Figure 16 compares the bending moment variation for the two fire conditions. For the ISO 834 fire, it is observed that the rotational restraint influences the maximum value of the bending moment, but not the survival time of the structure (around $1500 \mathrm{sec}$ ); however under the heatingcooling fire, it is observed that for the case c) the beam fails during the cooling phase due to the high cooling axial force (Figure 17) while the other beams behave similarly until the maximum studied time $(3600 \mathrm{sec})$.
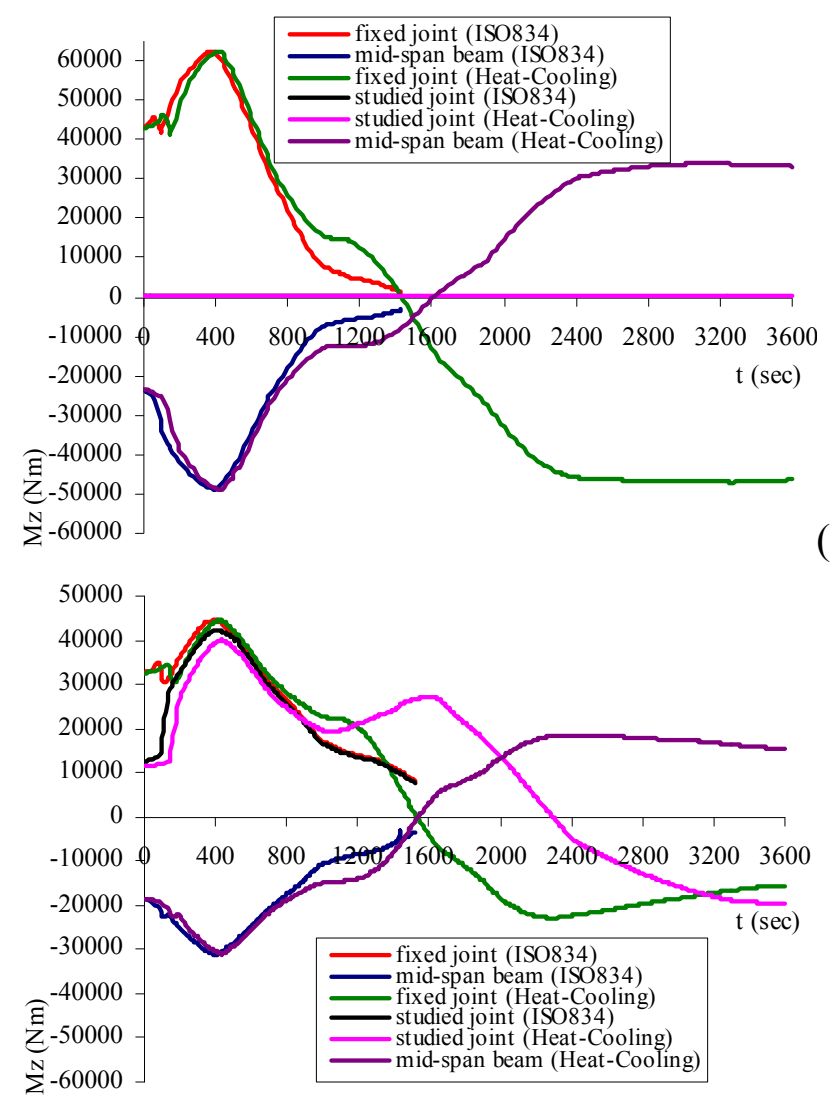

(case 2a)

(case $2 b)$

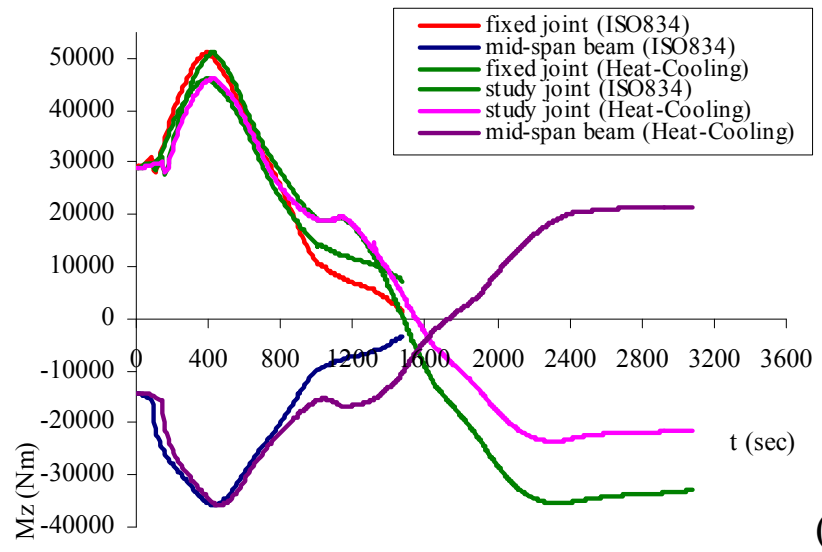

(case 2c)

Fig. 16 Development of beam moment. 


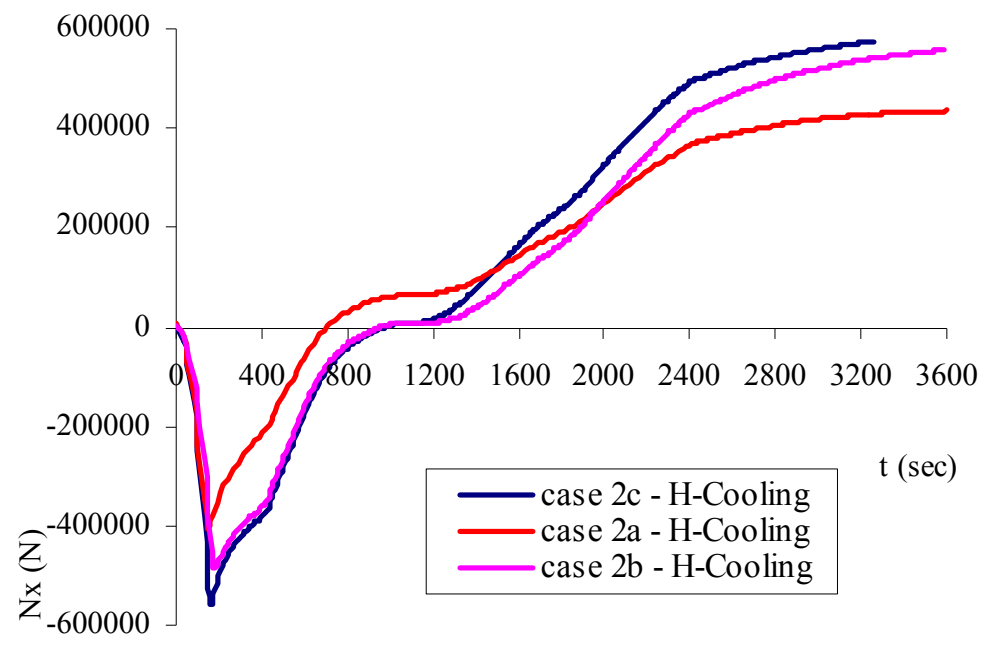

Fig. 17 Development of axial force.
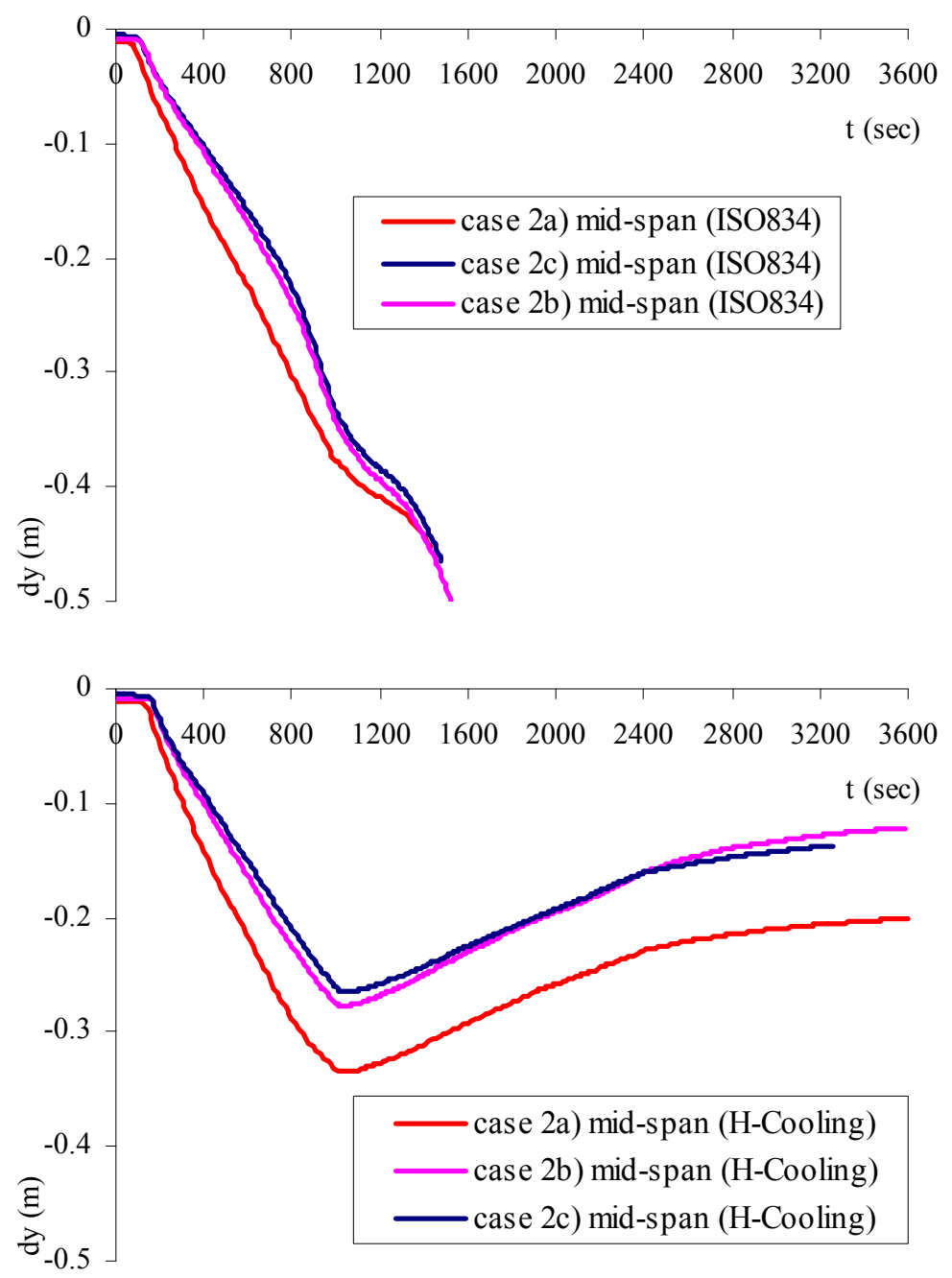

Fig. 18 Development of beam mid-span deflection. 
Examination of Figures 18 and 19, shows that the mid-span deflection variation is not much influenced by the rotational restraint; however the rotational displacement at the beam end is highly dependent of this parameter, as expected. If cooling is allowed before failure, the vertical displacement and the joint rotation decrease significantly.
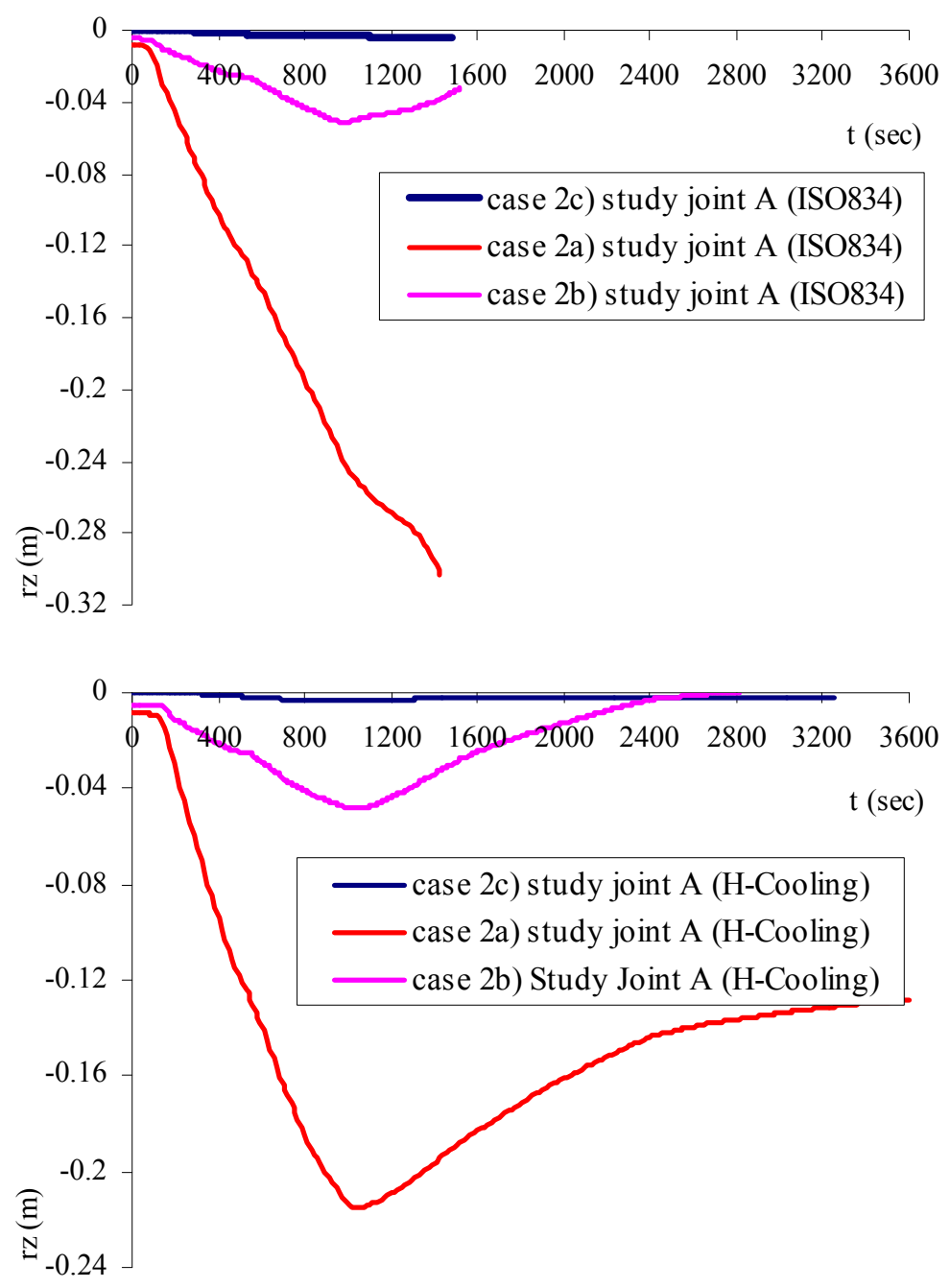

Fig. 19 Development of rotational displacement at joint A

\section{Conclusions}

The evaluation of the behaviour of steel beams under a standard ISO fire, whereby the temperature increases monotonically, or a real fire, characterized by a heating and a cooling phase, considering the influence of different boundary conditions, is discussed in this paper. It is found that, compared to the usual assumptions of "standard" fire experiments (ISO 834 fire curve and simplysupported boundary conditions), the results are quite distinct. 
Firstly, even for low axial restraint, an initial increase of bending moment is noted as the temperature increases, that can double the value of the bending moment. This is followed by a reduction of bending moment and axial force, with complete reversal of the bending moment diagram in case of a real fire.

Secondly, a parametric variation of the rotational restraint at the beam end reveals the same qualitative behaviour as before, the maximum moment approximately reaching the same value, independently of the level of rotational restraint at the beam end.

The numerical analyses described in this paper thus indicate that strain reversal plays an important role in the behaviour of real structures, being essential to assess the residual safety of fire damaged buildings. Additionally, this strain reversal redistributes high levels of tensile forces to the joints, eventually leading to a tensile failure of the less ductile components such as bolts or welds. This latter issue still remains to be explored. Finally, the possibility of a 3D behaviour of the beam, where lateral-torsional buckling plays a major role, already observed in recent fire tests is an issue being actively explored.

\section{References}

[1] CEN, Eurocode 1, Draft prEN - 1991-1-2: 200x, Part 1.2: General actions Actions on structures exposed to fire, Eurocode 1: Actions on structures, Final Draft, April 2002, CEN, European Committee for Standardization, Brussels, 2002.

[2] L. Simões da Silva, A. Santiago and P. Vila Real, "A component model for the behaviour of steel joints at elevated temperatures", J. of Constructional Steel Research, 57(11), 1169-1195, 2001.

[3] CEN, Eurocode 3, Draft prEN - 1993-1-2: 200x, Part 1.2: Structural Fire Design, Eurocode 3: Design of Steel Structures, Stage 34, February 2002, CEN, European Committee for Standardization, Brussels, 2002.

[4] J.-M. Franssen, SAFIR. A Thermal/Structural Program Modelling Structures under Fire, Proc. NASCC 2003, A.I.S.C. Inc., Baltimore, April 2-4 (2003)

[5] CEN, Eurocode 3, Draft prEN - 1993-1-8: 200x, Part 1.8: Design of Joints, Eurocode 3: Design of Steel Structures, Stage 34 draft, 31 January 2003, CEN, European Committee for Standardization, Brussels, 2003.

[6] C.G. Bailey, I.W. Burgess, R.J. Plank, "Computer simulation of a full-scale structural fire test", The Structural Engineer, 74(6), 93-100, 1996. 